\title{
Patient Preferences for Change in Symptoms Associated with Opioid-Induced Constipation
}

\author{
Robert S. Epstein - Ali Cimen - Hannah Benenson - Ronald E. Aubert • \\ Mona Khalid $\cdot$ Mark B. Sostek $\cdot$ Tehseen Salimi
}

To view enhanced content go to www.advancesintherapy.com

Received: October 25, 2014 / Published online: November 21, 2014

(c) The Author(s) 2014. This article is published with open access at Springerlink.com

\section{ABSTRACT}

Introduction: While opioids have become a standard treatment option for those experiencing moderate to severe chronic pain, side effects of constipation and related symptoms have interfered with their usage in as many as $40-50 \%$ of treated patients. Prior research has elucidated the range of these symptoms, but no study has determined which of these symptoms patients most desire improving or whether improving constipation itself by as little as one more bowel movement per week is deemed an important change.

Electronic supplementary material The online version of this article (doi:10.1007/s12325-014-0169-x) contains supplementary material, which is available to authorized users.

R. S. Epstein $(\varangle) \cdot$ R. E. Aubert · M. Khalid Epstein Health, 50 Tice Boulevard Suite 340, Woodcliff Lake, NJ 07677, USA

e-mail: repstein@epsteinhealth.com

A. Cimen

AstraZeneca, Cambridge, UK

H. Benenson

Brown University, Providence, RI, USA

M. B. Sostek · T. Salimi

AstraZeneca, Gaithersburg, MD, USA
Methods: We conducted an online patient survey of 513 participants residing in one of six countries who reported having chronic pain, were taking opioids, and experiencing opioidinduced constipation (OIC) to address these questions.

Results: Respondents rank ordered their preferences and the following eight symptoms generated $>80 \%$ endorsement as important to improve: improvement in having bowel movements without rectal pain, soft stools that are not loose or watery, regular bowel movements, a reduction in rectal straining, relief from feeling bloated, feeling less fear about having OIC when following their opioid medication regime, a desire to worry less overall about having a bowel movement, and with less 'stomach' area pain. When asked 'how important is it you to have 1 more bowel movement per week", over 90\% endorsed it was 'somewhat', 'very', or 'extremely important' with nearly $70 \% \quad(n=354)$ endorsing the 'extremely' or 'very important' response options. In multivariate models, being in more overall pain or reporting fewer than 3 bowel movements per week were found to be independent predictors of the importance. 
Conclusions: These results highlight the notable range of OIC symptoms most desired by patients to improve and demonstrate that bowel movements of only one more per week were important to register a meaningful improvement. The latter is particularly helpful for those assessing the minimal clinically important difference in treating this condition.

Keywords: Burden; Chronic pain; Constipation; Opioid-induced constipation; Opioids; Patient; Symptoms

\section{INTRODUCTION}

Over the past 20 years, patients have increasingly been prescribed long-term courses of opioids for relief of their chronic musculoskeletal or cancer pain [1]. While the central nervous system effects of these drugs have clearly helped ease the painful discomfort and improve quality of life for those afflicted, off-target side effects on the gastrointestinal tract are noted in as many as $40-50 \%$ of these patients [2-7]. These side effects are predominantly a very noticeable and unrelenting chronic constipation, the so-called opioid-induced constipation (OIC), which occurs within the first weeks of opioid treatment. To date, OIC is largely addressed by lifestyle modification in terms of increasing dietary fiber, rotating courses of therapy with alternative opioids or by taking concomitant laxatives or stool softeners [8]. Despite these approaches, nearly $50 \%$ of OIC patients do not improve and for many, their symptoms are bothersome enough to lead to lowering or even skipping their opioid doses to improve their debilitating constipation [9].

A variety of studies have sought to characterize the patient experience of both the nature of OIC-related discomfort and its impact on activities of daily living and ensuing quality of life. The symptoms of OIC frequently cited include having fewer than three bowel movements per week, bloating, cramping, infrequent passage of hard stools, straining, spasms, flatulence, hard and dry stools, nausea, vomiting, abdominal pain and reflux $[2,4,8,10-12]$. The impact of these symptoms has been shown to lead to impairment in the activities of daily living and work productivity $[13,14]$.

While it is clear that the hallmark of OIC is to experience infrequent bowel movements, it is not clear from prior patient research $[10,11]$ which of all the myriad OIC symptoms previously studied are the most important ones that patients would prefer to improve upon. Additionally, there is a lack of prior research to determine the effect size or degree of improvement patients are seeking in terms of increasing the number of bowel movements they experience per week due to OIC. The purpose of the present study was therefore to survey OIC patients to identify which of their many symptoms were viewed as those most important to be improved upon. We also sought to establish whether an increase of one more bowel movement per week was deemed sufficient to make a difference to patients suffering from OIC.

\section{METHODS}

The study was designed as a cross-sectional, geographically dispersed online self-reported survey of patients experiencing OIC. Questions were designed with responses to be both categorical, using various scales, and also incorporate open-ended text to fully elucidate the nuances of the impact of OIC on patients' 
lives. The results from the free-text or qualitative responses are the subject of a separate paper.

Study participants were drawn from a large online patient database of over 800,000 individuals, and sampled within the following six countries: US, UK, Canada, Germany, Sweden and Norway. Participants were screened via e-mail and if they met the inclusion criteria, they were invited to participate in an online survey. The inclusion criteria were defined by each respondent meeting all of the following: minimum 18 years of age; self-reporting of chronic noncancer pain; noting at least two active symptoms of OIC; taking a chronic course of opioid medications; confirming an ability to read or speak the language of the country the survey was administered; and a willingness and ability to provide written consent for participation.

The target sample size for the convenience sample was 500 respondents indicating they had OIC. Surveys were collected in May 2014 via a secured, online web-based survey system (HealthiVibe, LLC, Arlington, VA, USA). To do so, eligible participants were directed to a secure URL to access the survey that comprised a series of multiple-choice, closed-ended and free-text questions, which took approximately 12-15 min to complete.

The primary objectives of interest were to determine those symptoms of OIC that most patients ( $>80 \%$ ) would prefer to improve, and to determine whether one more bowel movement per week was considered 'extremely' or 'very' important to them, as phrased in the question: "How important is it to you to have one more bowel movement per week?" Pre-planned additional analyses were envisioned to determine which various potential patient subgroups were more or less likely to endorse this degree of symptomatic improvement.

Specific opioid drugs used by respondents were later dichotomized into a categorical variable with pharmacologically weak vs. strong opioids as follows: weak (tramadol, hydrocodone, codeine, dihydrocodeine) or strong (morphine, oxycodone, fentanyl, hydromorphone, methadone).

\section{Statistical Analysis}

Chi-square tests were used to assess bivariate associations for categorical variables. $t$ tests assuming non-equal variance were used to evaluate differences for bivariate continuous variables. Logistic regression models were used to assess factors associated with participants agreeing that one more bowel movement per week was sufficient to be 'extremely' or 'very' important to them (vs. those stating it was only 'somewhat' or 'not' important). The regression model included participant age, gender, reporting of strong vs. weak opioid usage, severity of chronic pain on a scale of 0-10 (with increasing pain represented by increasing score), presence or absence of neuropathic pain, having fewer or more than three spontaneous bowel movements per week, and place of residence being a European or North American locale. Odds ratios were estimated to measure strengths of association and 95\% confidence limits were estimated to assess precision. A $P$ value $<0.05$ was used to determine statistical significance. All analyses were performed using SAS version 9.4 (SAS Institute Inc., Cary, NC, USA).

\section{Compliance with Ethics Guidelines}

This article does not contain any new experimental studies with human or animal subjects performed by any of the authors. 


\section{RESULTS}

As noted in Table 1, a total of 513 participants engaged in providing their input in the online survey. They were, on average, 46 years of age, with 55\% female, $88.5 \%$ Caucasian, and most having at least high school education. There were approximately 100 (20\%) participants from each of the following countries: US, Canada, Germany and the UK. The combined participation rate from the Nordic countries comprised 72 participants or $14.1 \%$ of the total sample. Very few participants (11\%) self-reported being in either 'excellent' or 'very good' health (Table 2). Participants could list multiple reasons for their chronic pain, with more than two-thirds indicating they had either back or musculoskeletal pain. Their average degree of pain on a $0-10$ scale was 6.7 , and they reported having their pain for a mean of 10.6 years. A little more than half reported taking pharmacologically strong opioids, while slightly fewer than half reported taking weaker opioids.

Table 1 Baseline characteristics of participants

\begin{tabular}{lc}
\hline Characteristic & $\begin{array}{c}\text { Participants } \\
(\boldsymbol{n}=\mathbf{5 1 3})\end{array}$ \\
\hline Mean (SD) age, years & $46.1(13.0)$ \\
Female, $n$ (\%) & $282(55)$ \\
Country of residency, $n$ (\%) & \\
US & $112(21.8)$ \\
Canada & $113(22.0)$ \\
UK & $117(22.8)$ \\
Germany & $99(19.3)$ \\
Sweden & $50(9.7)$ \\
Norway & $22(4.3)$ \\
Caucasian, $n$ (\%) & $454(88.5)$ \\
$<$ High school graduate (or equivalent), & $40(7.8)$ \\
$n$ (\%) & \\
\hline$S D S$
\end{tabular}

$S D$ Standard deviation
The improvements that more than $80 \%$ of participants with OIC would prefer to see are to have bowel movements without pain, soft stools that are not loose or watery, a reduction in rectal straining, and relief from feeling bloated (see Table 3). Additionally, more than $80 \%$ of participants with OIC would prefer to feel less fear about having OIC when they followed their opioid medication regime, worry less overall about having a bowel movement, and have less 'stomach' area pain. $79.3 \%$ of participants also stated they would prefer to avoid taking laxatives or suppositories to help with their constipation.

Being able to have a bowel movement on a 'regular' basis was considered an important symptom to improve upon by more than $86 \%$ of the respondents. When asked, "How important is it for you to have one more bowel movement per week?" over 90\% responded that it was 'somewhat', 'very', or 'extremely' important, with over 70\% $(n=354)$ supporting the 'extremely' or 'very' important response options (Table 4). Respondents from the Nordic countries appeared to vary slightly in their response to this question compared with respondents from other countries in that $48 \%$ (Norway) and 57\% (Sweden) considered one more bowel movement per week as being 'very' or 'extremely' important, compared with $70-83 \%$ of respondents from the other countries surveyed. Overall, only 3.9\% of respondents felt that having one more bowel movement would not be an important difference representing an improvement in their condition. The remaining $4.3 \%$ of respondents indicated that they did not know whether one more bowel movement per week would make a difference to them and were not included in the table.

Nearly, $60 \%$ of respondents noted that they took less of their pain medication when they were constipated: $10 \%$ stated they 'always' took 
Table 2 Clinical characteristics of participants

\begin{tabular}{lc}
\hline Characteristics & $\begin{array}{c}\text { Participants } \\
(\boldsymbol{n}=\mathbf{5 1 3})\end{array}$ \\
\hline Self-rating of health, $n$ (\%) & $13(2.5)$ \\
Excellent & $46(8.9)$ \\
Very good & $185(36.1)$ \\
Good & $185(36.1)$ \\
Fair & $84(16.4)$ \\
Poor & \\
Reason for pain, $n$ (\%) & $409(79.7)$ \\
Back pain & $104(20.3)$ \\
Fibromyalgia & $254(49.5)$ \\
Headache & $358(69.8)$ \\
Joint pain & $144(28.1)$ \\
Nerve damage & $145(28.3)$ \\
Osteoarthritis & $106(20.7)$ \\
Pain syndrome & $119(23.2)$ \\
Rheumatoid arthritis & $6.7(1.6)$ \\
Mean (SD) rating of pain & $10.6(9.5)$ \\
(in the past week) on a $0-10$ scale & \\
Mean (SD) duration of pain, years & $298(58.1)$ \\
Participants taking opioids by type, $n(\%)$ & $215(41.9)$ \\
Strong opioids & \\
Weak opioids & \\
\hline &
\end{tabular}

$S D$ Standard deviation

less pain medication while constipated, while an additional $19 \%$ stated they 'usually' took less pain medication; 30\% stated they 'sometimes' took less.

Table 5 shows a comparison of some of the categorical factors evaluated for their association with the participants' response that having one more bowel movement per week was important. Numerically, more than $70 \%$ of younger adults ( $<65$ years) felt that having one more bowel movement per week was 'extremely' or 'very' important compared with
$56 \%$ of those aged $\geq 65$ years, though these differences were not statistically significant (it should be noted, however, that the sample size of those $\geq 65$ years was small). As might be expected, more participants who had either fewer than three bowel movements per week or were in more severe pain endorsed the importance of having one more bowel movement per week.

Figure 1 displays the box-and-whisker plot of results from the logistic regression equation to examine which of the factors were independently related to endorsing the importance of experiencing a single additional bowel movement per week. Again, being in more overall pain or reporting fewer than three bowel movements per week were found to be independent predictors, while age, gender, pharmacological strength of opioid taken, and geography of residence were not found to be predictors.

\section{DISCUSSION}

Many studies have sought to understand the range of symptoms experienced by people living with OIC, though none have been designed to understand patients' specific preferences for which aspects are most important to improve. In our study, we found that more than $80 \%$ of 513 participants across six countries endorsed seeking an improvement in eight particular areas of concern that ranged from having regular bowel movements to assuaging fear and worry related to their condition. For individuals involved with the clinical monitoring of patients with OIC to detect an improvement in constipation, a specific focus on these symptoms seems warranted.

It is interesting that most patients in our study viewed having one more bowel 
Table 3 Aspects of constipation most $(\geq 80 \%)$ participants would prefer to improve

\begin{tabular}{ll}
\hline Aspect & $\begin{array}{l}\text { Participants in } \\
\text { agreement, \% }\end{array}$ \\
\hline $\begin{array}{l}\text { Be able to have a bowel movement } \\
\text { without pain }\end{array}$ & 87.9 \\
$\begin{array}{l}\text { Be able to have a soft stool that is not } \\
\text { loose or watery }\end{array}$ & 87.1 \\
$\begin{array}{l}\text { Not experience rectal straining due to } \\
\text { my constipation }\end{array}$ & 83.4 \\
$\begin{array}{l}\text { Feel less bloated } \\
\text { Be more comfortable using my opioid } \\
\text { medication without fear of being } \\
\text { constipated }\end{array}$ & 82.1 \\
$\begin{array}{l}\text { Worry less about being able to have a } \\
\text { bowel movement }\end{array}$ & 80.5 \\
\begin{tabular}{l} 
Have less pain in my stomach area \\
\hline
\end{tabular} & 80.3 \\
\hline
\end{tabular}

Table 4 Participants who considered that $\geq 1$ more bowel movement per week was an important change

\begin{tabular}{lll}
\hline Country & \multicolumn{2}{l}{ Participants (\%) who considered the change } \\
\cline { 2 - 3 } & $\begin{array}{l}\text { At least 'somewhat' } \\
\text { important }\end{array}$ & $\begin{array}{l}\text { 'Very' or 'extremely' } \\
\text { important }\end{array}$ \\
\hline Canada & 99 & 83 \\
Germany & 96 & 70 \\
Norway & 90 & 48 \\
Sweden & 87 & 57 \\
US & 97 & 72 \\
UK & 97 & 74 \\
Overall & 96 & 72 \\
\hline
\end{tabular}

a Respondents endorsed this change as 'somewhat', 'very' or 'extremely' important

movement per week as 'extremely' or 'very' important. This is a very telling finding in that even a seemingly small change was not deemed small to these patients. Clearly, the impact of OIC is important to these patients and a change is desired. While the study did not have sufficient statistical power to find a difference, numerically, those participants who were younger than 65 years of age appeared to be even more sensitive to this level of improvement. It is not surprising, as others have noted that OIC can adversely affect both workplace productivity and activities of daily living [10], and those under the age of 65 are particularly vulnerable to either issue.

Our study noted a high proportion (60\%) of patients who responded that they reduced their pain medication as a result of their constipation. Prior research with intervieweradministrated questionnaires, as opposed to our anonymized online survey, may result in social desirability response bias [15], where the respondent seeks to please the interviewer and not provide responses that are counter to the interviewer's desire. Patient responses admitting to a self-initiated reduction in prescribed medication is not easy for patients. Therefore, our use of an anonymized online survey may have allowed a more honest response to this question leading to a seemingly high response confirming that patients reduced their pain medication.

It was noticeable that participants in our study who had chronic pain and were taking opioids experienced OIC scores much lower on the frequently utilized epidemiologic question asking patients to self-rate their overall general health. In a recent evaluation of the US National Health and Nutritious Examination Survey (NHANES) data, $17 \%$ of a representative sample of US residents reported their health as 'excellent' and 32\% reported it as 'very good' [16]. In our study, only $2.5 \%$ of respondents reported their health as 'excellent' with $8.9 \%$ reporting being in 'very good' health. Interestingly, a recently published study of similarly defined OIC participants found that only $1.4 \%$ of participants reported their health 
Table 5 Bivariate analyses of selected patient factors in relation to the belief that one more bowel movement per week would make an important difference in OIC symptoms

\begin{tabular}{|c|c|c|c|c|c|}
\hline \multirow[t]{2}{*}{ Factor } & \multicolumn{5}{|c|}{$\begin{array}{l}\text { Response (\%) to the question, "How important is it to you to have one more bowel movement per } \\
\text { week?" }\end{array}$} \\
\hline & Extremely & Very & Somewhat & Not & $P$ value \\
\hline \multicolumn{6}{|l|}{ Age, years } \\
\hline$<65(n=468)$ & 37.2 & $33.1 \%$ & 21.6 & 3.9 & \\
\hline$\geq 65(n=45)$ & 26.7 & 28.9 & 35.6 & 4.4 & 0.2841 \\
\hline \multicolumn{6}{|c|}{ Weekly number of bowel movements } \\
\hline$<3(n=225)$ & 40.9 & 35.6 & 18.7 & 1.3 & \\
\hline$\geq 3(n=288)$ & 32.6 & 30.6 & 26.0 & 5.9 & 0.0086 \\
\hline \multicolumn{6}{|c|}{ Mean pain score in the past week on a scale of $0-10$} \\
\hline$\leq 7(n=369)$ & 32.5 & 33.1 & 26.0 & 4.3 & \\
\hline$>7(n=144)$ & 45.8 & 31.9 & 14.6 & 2.8 & 0.0186 \\
\hline
\end{tabular}

Percentages may not sum to $100 \%$ as some participants indicated 'don't know' and are not depicted here. A response of 'don't know' did not exceed $>5 \%$

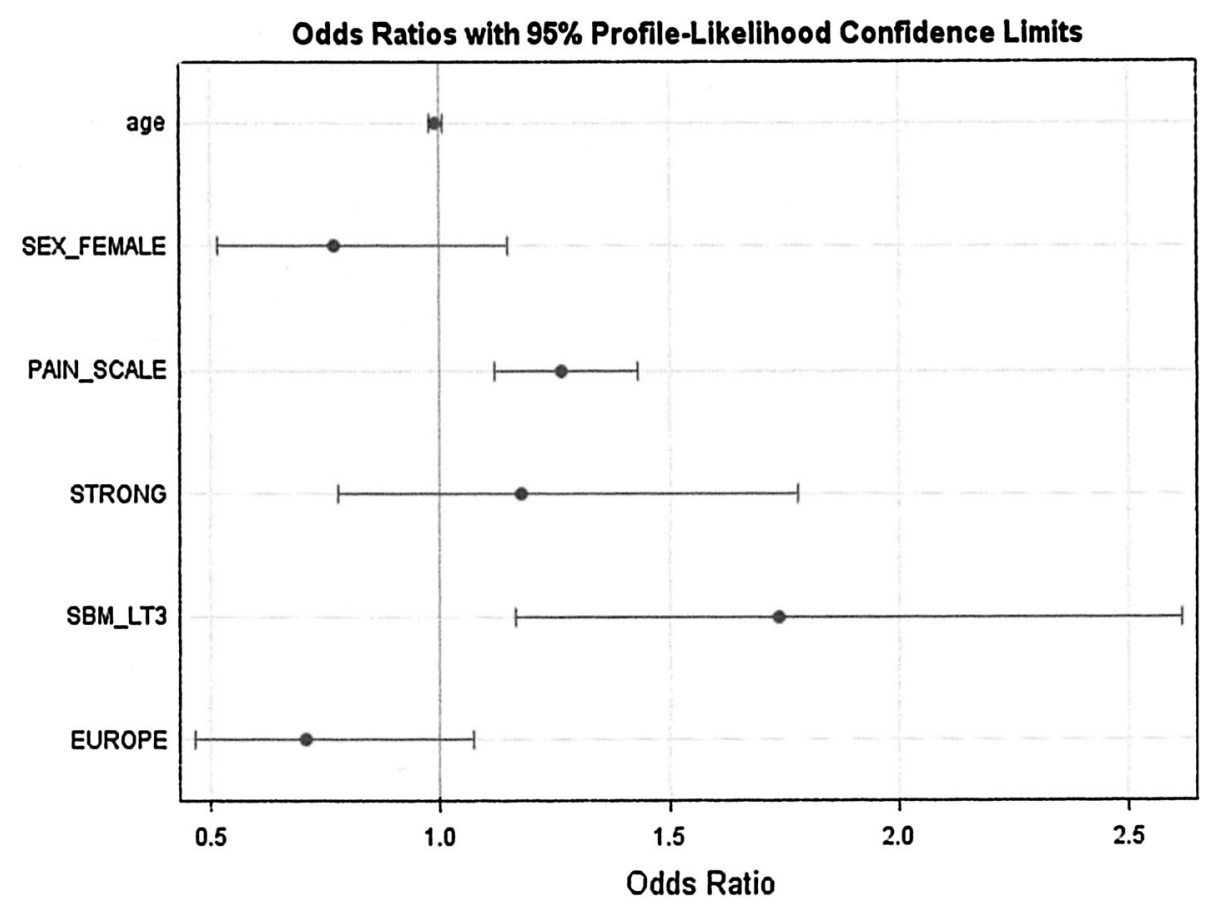

Fig. 1 Factors independently related to the response that having one more bowel movement per week was 'extremely' or 'very' important vs. all other responders. PAIN_SCALE refers to the numeric $0-10$ response to the pain severity question; SBM_LT3 refers to whether the patient had fewer than 3 spontaneous bowel movements per week 
as 'excellent' and $6.7 \%$ as 'very good'; very close to our findings [10]. We were not able to study the contribution of constipation to the diminished self-rated responses to general health perception, but it would be useful for future researchers to consider determining the degree to which the underlying physical reason for pain, the use of opioids, and/or the side effects of OIC contribute to these overall low ratings.

A potential limitation of our study was the way in which we drew our study sample from an online patient database. This could bias in favor of reflecting the preferences of a higher socioeconomic background than the average person with OIC. By definition, our participants had to be internet-savvy, and able and willing to participate in a web-based study. The fact that $>90 \%$ of our participants had completed at least high school education reflects their potentially high socioeconomic status. Yet, the demographic, clinical characteristics and overall health of our participants were very similar to those noted in a recently published study whose participants were drawn from primary care clinics, pain management clinics and clinical research sites across some of the same countries we studied (US, Canada, Germany, UK) [10]. So while it may be that our participants were better educated, it does appear that they are otherwise similar to those OIC patients identified by other means.

Another limitation of our study was the lack of daily dosages of pain medications. However, we were able to obtain the name of the specific opioid and later stratified them into strong or weak opioids. The addition of daily dosage could have refined our analyses further.

Our study enrolled a relatively small sample size of older respondents. Our analysis of age in relation to the impact of OIC suggests that the problems and desired solutions were more pronounced among younger ( $<65$ years) than older ( $\geq 65$ years) respondents. Future research should seek to enroll a wider age range to tease out the influence of age on desired health state.

\section{CONCLUSIONS}

Our study is the first to identify which of many OIC symptoms are most important to detect clinically meaningful improvement from a patient perspective. Additionally, we found that over $90 \%$ of patients reported that one more bowel movement per week was considered an important improvement in this overall problem, which is associated with chronic opioid usage. This degree of improvement may serve as an effect size or minimal clinically important difference for future research studies that seek to improve the condition of patients suffering from OIC.

\section{ACKNOWLEDGMENTS}

Sponsorship and article processing charges for this study was funded by AstraZeneca. All named authors meet the ICMJE criteria for authorship for this manuscript, take responsibility for the integrity of the work as a whole, and have given final approval for the version to be published.

The authors are grateful for the contributions of Abbe Steel and Megan Leone-Perkins PhD in the conduct of the online study and JoAnn Krenitsky for her overall project management.

Conflict of interest. Robert Epstein serves on the Boards of Directors of Illumina, Proteus Digital, and Fate Therapeutics, and has consulted with a variety of life science companies, including AstraZeneca. Ali Cimen is an employee and shareholder of AstraZeneca. 
Hannah Benenson declares no conflict of interest. Ronald Aubert has consulted with a variety of life science companies, including AstraZeneca. Mona Khalid has consulted with a variety of life science companies, including AstraZeneca. Mark Sostek is an employee and shareholder of AstraZeneca. Tehseen Salimi is an employee and shareholder of AstraZeneca.

Compliance with ethics guidelines. This article does not contain any new experimental studies with human or animal subjects performed by any of the authors.

Open Access. This article is distributed under the terms of the Creative Commons Attribution Noncommercial License which permits any noncommercial use, distribution, and reproduction in any medium, provided the original author(s) and the source are credited.

\section{REFERENCES}

1. Quigley C. Opioid switching to improve pain relief and drug tolerability. Cochrane Database Syst Rev. 2004;3:CD004847.

2. Pappagallo M. Incidence, prevalence, and management of opioid bowel dysfunction. Am J Surg. 2001;182(5A Suppl.):11S-8S.

3. Bell TJ, Panchal SJ, Miaskowski C, Bolge SC, Milanova T, Williamson R. The prevalence, severity and impact of opioid-induced bowel dysfunction: results of a US and European patient survey (PROBE 1). Pain Med. 2009;10:35-42.

4. Panchal SJ, Müller-Schwefe P, Wurzelmann JI. Opioid-induced bowel dysfunction: prevalence, pathophysiology and burden. Int J Clin Pract. 2007;61:1181-7.

5. Brown RT, Zuelsdorff M, Fleming M. Adverse effects and cognitive function among primary care patients taking opioids for chronic nonmalignant pain. J Opioid Manag. 2006;2:137-46.
6. Cook SF, Lanza L, Zhou X, et al. Gastrointestinal side effects in chronic opioid users: results from a population-based survey. Aliment Pharmacol Ther. 2008;27:1224-32.

7. Allan L, Jensen $\mathrm{H}$, Hays $\mathrm{NH}$, et al. Randomised crossover trial of transdermal fentanyl and sustained release oral morphine for treating chronic non-cancer pain. BMJ. 2001;322:1154-8.

8. Dorn S, Lembo A, Cremonini F. Opioid-induced bowel dysfunction: epidemiology, pathophysiology, diagnosis, and initial therapeutic approach. Am J Gastroenterol. 2014;2:31-7.

9. Cherny N, Ripamonti C, Pereira J, et al. Strategies to manage the adverse effects of oral morphine: an evidence-based report. J Clin Oncol. 2001;19:2542-54.

10. Coyne KS, LoCasale RJ, Datto CJ, Sexton CC, Yeomans K, Tack J. Opioid-induced constipation in patients with chronic noncancer pain in the USA, Canada, Germany, and the UK: descriptive analysis of baseline patient-reported outcomes and retrospective chart review. Clinicoecon Outcomes Res. 2014;6:269-81.

11. Dinghra L, Shuk E, Grossman B, et al. A qualitative study to explore psychological distress and illness burden associated with opioid-induced constipation in cancer patients with advanced disease. Palliat Med. 2013;27:447-56.

12. Camilleri M, Drossman DA. Emerging treatments in neurogastroenterology: a multidisciplinary working group consensus statement on opioid induced constipation. Neurogastroenterol Motil. 2014;10:1386-95.

13. Penning-van-Beest FJ, van den Haak P, Klok RM, Prevoo YF, van der Peet DL, Herings RM. Quality of life in relation to constipation among opioid users. J Med Econ. 2010;13:129-35.

14. Leslie J, Bell T, Annunziata K, Freedman D. Opioidinduced constipation compromises pain management and impacts patient quality of life. Anesthesiology. 2006;105:Abstr 1490.

15. Nederhof AJ. Methods of coping with social desirability bias: a review. Eur J Soc Psychol. 1985;15:263-80.

16. Zajacova A, Dowd JB. Reliability of self-related health in US adults. Am J Epidemiol. 2011;174:977-83. 